\title{
A Note on Quasi-coincidence for Fuzzy Points of Fuzzy Topology on the Basis of Reference Function
}

\author{
Kangujam Priyokumar Singh ${ }^{a}$, Bhimraj Basumatary ${ }^{b, *}$ \\ ${ }^{a}$ Department of Mathematical Sciences, Bodoland University, Kokrajhar, BTC, Assam,783370, India \\ ${ }^{b}$ Department of Mathematical Sciences, Bodoland University, Kokrajhar, BTC, Assam,783370, India
}

\begin{abstract}
In this article our main aim is to revisit the definition of fuzzy point and fuzzy quasi-coincident of fuzzy topology which is accepted in the literature of fuzzy set theory. We analyse some results and also prove some proposition with extended definition of complementation of fuzzy sets on the basis of reference function and some new definitions have also been introduced whenever possible. In this work the main efforts have been made to show that the existing definition of complement of fuzzy point and definition of fuzzy quasi-coincident are not acceptable.
\end{abstract}

Index Terms: Fuzzy Point, Fuzzy Quasi-Coincident, Fuzzy Topology.

(C) 2016 Published by MECS Publisher. Selection and/or peer review under responsibility of the Research Association of Modern Education and Computer Science

\section{Introduction}

Fuzzy set theory was discovered by Zadeh [1] in 1965. The theory of fuzzy sets actually has been a generalization of the classical theory of sets in the sense that the theory of sets should have been a special case of the theory of fuzzy sets. But unfortunately it has been accepted that for fuzzy set A and its complement $\mathrm{A}^{\mathrm{C}}$, neither $\mathrm{A} \cap \mathrm{A}^{\mathrm{C}}$ is empty set nor $\mathrm{AU}_{\mathrm{A}}{ }^{\mathrm{C}}$ is the universal set. Whereas the operations of union and intersection of crisp sets are indeed special cases of the corresponding operation of two fuzzy sets, they end up giving peculiar results while defining $\mathrm{A} \cap \mathrm{A}^{\mathrm{C}}$ and $\mathrm{A} \mathrm{U}_{\mathrm{A}}^{\mathrm{C}}$. In this regard Baruah [2, 3] has forwarded an extended definition of complement of fuzzy sets which enable us to define complement of fuzzy sets in a way that give us $\mathrm{A}_{\mathrm{A}} \mathrm{C}$ is empty and $\mathrm{A}_{\mathrm{A}}^{\mathrm{C}}$ is universal set.

* Corresponding author. Basumatary B. +919508908682

E-mail address: brbasumatary14@gmail.com 
Chang [4] introduced fuzzy topology. After the introduction of fuzzy sets and fuzzy topology, several researches were conducted on the generalizations of the notions of fuzzy sets and fuzzy topology. In fuzzy topology also many results are not same as general topology. It is seen that when we used the existence definition of fuzzy set in fuzzy boundary then closure of any fuzzy set is not equal to union of a fuzzy set and its boundary. The main reason behind it is expression of complement of existing definition of fuzzy set. Present author [5] has expressed nicely in this regard with extended definition of fuzzy set and showed that closure of a fuzzy set is equal to union of a fuzzy set and its boundary.

In this article we apply the extended definition of complementation of fuzzy sets on the basis of reference function to give definition of fuzzy point and quasi-coincidence of fuzzy topology and try to prove some results on quasi-coincidence for fuzzy point so that we can get result more accuracy than before.

\section{Related Work}

To avoid difficulty of complement of fuzzy set many new ideas were developed. The concept of intuitionistic fuzzy set was introduced by Atnassov [6] as a generalization of fuzzy set. By observing this idea in 1997 Coker [7] introduced the concept of intuitionistic fuzzy topology. Pu and Liu [8] were discussed on Fuzzy topology I neighbourhood structure of a fuzzy point and Moore-Smith convergence. Coker and Demirci [9] were explained very nicely on intuitionistic fuzzy points. In this article we would discuss fuzzy point and fuzzy quasi coincident on the basis of extended definition of fuzzy set.

\section{Baruah's Definition of Complementation of Fuzzy Sets}

Baruah [2, 3] gave an extended definition of complementation of fuzzy set. According to Baruah [2, 3] to define a fuzzy set, two functions namely fuzzy membership function and fuzzy reference function are necessary. Fuzzy membership value is the difference between fuzzy membership function and fuzzy reference function.

Let $\mu_{1}(x)$ and $\mu_{2}(x)$ be two functions such that $0 \leq \mu_{2}(x) \leq \mu_{1}(x) \leq 1$. For fuzzy number denoted by $\left\{x, \mu_{1}(x)\right.$, $\left.\mu_{2}(\mathrm{x}) ; \mathrm{x} \in \mathrm{U}\right\}$, we call $\mu_{1}(\mathrm{x})$ as fuzzy membership function and $\mu_{2}(\mathrm{x})$ a reference function such that $\left(\mu_{1}(\mathrm{x})-\mu_{2}(\mathrm{x})\right)$ is the fuzzy membership value.

\section{Basic Operations} U.

Let $A=\left\{x, \mu_{1}(x), \mu_{2}(x) ; x \in U\right\}$ and $B=\left\{x, \mu_{3}(x), \mu_{4}(x) ; x \in U\right\}$ be two fuzzy sets defined over the same universe

1. $\mathrm{A} \subseteq \mathrm{B}$ iff $\mu_{1}(\mathrm{x}) \leq \mu_{3}(\mathrm{x})$ and $\mu_{4}(\mathrm{x}) \leq \mu_{2}(\mathrm{x})$ for all $\mathrm{x} \in \mathrm{U}$.

2. $A \cup B=\left\{x, \max \left(\mu_{1}(x), \mu_{3}(x)\right), \min \left(\mu_{2}(x), \mu_{4}(x)\right)\right\}$ for all $x \in U$.

3. $A \cap B=\left\{x, \min \left(\mu_{1}(x), \mu_{3}(x)\right), \max \left(\mu_{2}(x), \mu_{4}(x)\right)\right\}$ for all $x \in U$.

If for some $\left.\mathrm{x} \in \mathrm{U}, \min \left(\mu_{1}(\mathrm{x}), \mu_{3}(\mathrm{x})\right) \leq \max \left(\mu_{2}(\mathrm{x}), \mu_{4}(\mathrm{x})\right)\right\}$, then our conclusion will be $\mathrm{A} \cap \mathrm{B}=\phi$

4. $\mathrm{A}^{\mathrm{C}}=\left\{\mathrm{x}, \mu_{1}(\mathrm{x}), \mu_{2}(\mathrm{x}) ; \mathrm{x} \in \mathrm{U}\right\}^{\mathrm{C}}=\left\{\mathrm{x}, \mu_{2}(\mathrm{x}), 0 ; \mathrm{x} \in \mathrm{U}\right\} \bigcup\left\{\mathrm{x}, 1, \mu_{1}(\mathrm{x}) ; \mathrm{x} \in \mathrm{U}\right\}$

5. If $D=\{x, \mu(x), 0 ; x \in U\}$ then $D^{C}=\{x, 1, \mu(x) ; x \in U\}$ for all $x \in U$.

Now we shall discuss some propositions regarding fuzzy topology considering the concepts of reference function, which are as follows:

\subsection{Proposition}


For fuzzy sets A, B, C over the same universe $\mathrm{X}$, we have the following proposition

$1.1 \quad \mathrm{~A} \subseteq \mathrm{B}, \mathrm{B} \subseteq \mathrm{C} \Rightarrow \mathrm{A} \subseteq \mathrm{C}$

$1.2 \mathrm{~A} \cap \mathrm{B} \subseteq \mathrm{A}, \mathrm{A} \cap \mathrm{B} \subseteq \mathrm{B}$

$1.3 \quad \mathrm{~A} \subseteq \mathrm{A} \cup \mathrm{B}, \mathrm{B} \subseteq \mathrm{A} \cup \mathrm{B}$

$1.4 \mathrm{~A} \subseteq \mathrm{B} \Rightarrow \mathrm{A} \cap \mathrm{B}=\mathrm{A}$

$1.5 \mathrm{~A} \subseteq \mathrm{B} \Rightarrow \mathrm{A} \cup \mathrm{B}=\mathrm{B}$

\subsection{Proposition}

Let $\tau=\left\{A_{i}: i \in I\right\}$ be a collection of fuzzy sets over the same universe $U$. Then

3.1. $\bigcup_{i} A_{i}=\left\{x, \max \left(\mu_{1 i}\right), \min \left(\mu_{2 \mathrm{i}}\right) ; \mathrm{x} \in \mathrm{U}\right\}$

3.2. $\bigcap_{i} \mathrm{~A}_{\mathrm{i}}=\left\{\mathrm{x}, \min \left(\mu_{1 \mathrm{i}}\right), \max \left(\mu_{2 \mathrm{i}}\right) ; \mathrm{x} \in \mathrm{U}\right\}$

\subsection{Proposition}

Let $\tau=\left\{A_{\mathrm{i}}: \mathrm{i} \in \mathrm{I}\right\}$ be a collection of fuzzy sets over the same universe $\mathrm{U}$. Then

3.1. $\left\{\bigcup_{i} \mathrm{~A}_{\mathrm{i}}\right\}^{\mathrm{C}}=\bigcap_{i} \mathrm{~A}_{\mathrm{i}}^{\mathrm{C}}$

3.2. $\left\{\bigcap_{i} \mathrm{~A}_{\mathrm{i}}\right\}^{\mathrm{C}}=\bigcup_{i}\left\{\mathrm{~A}_{\mathrm{i}}\right\}^{\mathrm{C}}$

\subsection{Proposition}

For a fuzzy set $A=\{x, \mu(x), \gamma(x) ; x \in U\}$.

$$
\left(A^{C}\right)^{C}=A \text {. }
$$

\subsection{Proposition}

For a fuzzy set A

1. $\mathrm{A} \cap \mathrm{A}^{\mathrm{C}}=\phi$

2. $\mathrm{A} \cup \mathrm{A}^{\mathrm{C}}=\mathrm{U}$.

4.6. Definition:

Let $\mathrm{X}$ and $\mathrm{Y}$ be two non empty sets and $\mathrm{f}: \mathrm{X} \rightarrow \mathrm{Y}$ be a function 
Let $B=\left\{y, \mu_{B}(y), \gamma_{B}(y): y \in Y\right\}$ be fuzzy set on $Y$, then preimage of $B$ under $f$ denoted by

$\mathrm{f}^{-1}(\mathrm{~B})$, is fuzzy set in $\mathrm{X}$ defined by

$f^{-1}(B)=\left\{x, f^{-1}\left(\mu_{B}\right)(x), f^{-1}\left(\gamma_{B}\right)(x): x \in X\right\}$, where $f^{-1}\left(\mu_{B}\right)(x)=\mu_{B}(f(x))$ and $f^{-1}\left(\gamma_{B}\right)(x)=\gamma_{B}(f(x))$.

If $A=\left\{x, \mu_{A}(x), \gamma_{A}(x)\right.$ : $\left.x \in X\right\}$ be fuzzy set in $X$, then image of $A$ under $f$ is denoted by $f(A)$ and defined as $f(A)(y)=\bigcup\left\{x \in X, f(x)=y, \mu_{A}(x), \gamma_{A}(x)\right\}$.

\subsection{Theorem}

Let $\mathrm{f}$ be a function from $\mathrm{X}$ to $\mathrm{Y}$. Then

1. $\mathrm{B}_{1} \subseteq \mathrm{B}_{2} \Rightarrow \mathrm{f}^{-1}\left[\mathrm{~B}_{1}\right] \subseteq \mathrm{f}^{-1}\left[\mathrm{~B}_{2}\right], \mathrm{B}_{1}$ and $\mathrm{B}_{2}$ are fuzzy sets in $\mathrm{Y}$.

2. $\mathrm{A}_{1} \subseteq \mathrm{A}_{2} \Rightarrow \mathrm{f}\left[\mathrm{A}_{1}\right] \subseteq \mathrm{f}\left[\mathrm{A}_{2}\right], \mathrm{A}_{1}$ and $\mathrm{A}_{2}$ are fuzzy sets in $\mathrm{X}$.

3. $B \supseteq f\left[f^{-1}[B]\right]$ for any fuzzy subset $B$ in $Y$.

4. $A \subseteq f^{-1}[f[A]]$ for any fuzzy subset $A$ in $X$.

5. $\mathrm{f}^{-1}[\cup \mathrm{B}]=\bigcup \mathrm{f}^{-1}[\mathrm{~B}]$

6. $\mathrm{f}^{-1}[\cap \mathrm{B}]=\bigcap \mathrm{f}^{-1}[\mathrm{~B}]$

7. $\mathrm{f}[\bigcup \mathrm{A}]=\bigcup \mathrm{f}[\mathrm{A}]$

8. $\mathrm{f}[\bigcap \mathrm{B}]=\bigcap \mathrm{f}[\mathrm{B}]$

\subsection{Theorems}

Let $\mathrm{f}$ be a function from $\mathrm{X}$ to $\mathrm{Y}$. Then

1. $\mathrm{f}^{-1}\left[1_{\mathrm{U}}\right]=1_{\mathrm{U}}$.

2. $\mathrm{f}^{-1}\left[0_{\mathrm{U}}\right]=0_{\mathrm{U}}$.

3. $\mathrm{f}^{-1}\left[\mathrm{~B}^{\mathrm{C}}\right]=\left\{\mathrm{f}^{-1}[\mathrm{~B}]\right\}^{\mathrm{C}}$ for any fuzzy set $\mathrm{B}$ in $\mathrm{Y}$.

4. $\{\mathrm{f}[\mathrm{A}]\}^{\mathrm{C}} \subseteq \mathrm{f}\left[\mathrm{A}^{\mathrm{C}}\right]$ for any fuzzy set $\mathrm{A}$ in $\mathrm{X}$.

It is clearly seen that the above theorems and propositions are also true when we use our extended definition of fuzzy set.

Now using our extended definition of fuzzy set we would like to discussed on fuzzy point and fuzzy quasicoincident of fuzzy topology.

\subsection{Definition}

A fuzzy topology on a nonempty set $\mathrm{X}$ is a family $\tau$ of fuzzy set in $\mathrm{X}$ satisfying the following axioms

(T1) $0_{\mathrm{X}}, 1_{\mathrm{X}} \in \tau$

(T2) $\mathrm{G}_{1} \cap \mathrm{G}_{2} \in \tau$, for any $\mathrm{G}_{1}, \mathrm{G}_{2} \in \tau$

(T3) $\bigcup \mathrm{G}_{\mathrm{i}} \in \tau$, for any arbitrary family $\left\{\mathrm{G}_{\mathrm{i}}: \mathrm{G}_{\mathrm{i}} \in \tau, \mathrm{i} \in \mathrm{I}\right\}$.

In this case the pair $(\mathrm{X}, \tau)$ is called a fuzzy topological space and any fuzzy set in $\tau$ is known as fuzzy open set in $\mathrm{X}$ and clearly every element of $\tau^{\mathrm{C}}$ is said to be fuzzy closed set.

Example: Let $\mathrm{X}=\{\mathrm{a}, \mathrm{b}\}$. 
Let $\mathrm{M}=\{(\mathrm{a}, 0.4,0),(\mathrm{b}, 0.5,0)\}, \mathrm{N}=\{(\mathrm{a}, 0.6,0),(\mathrm{b}, 0.8,0)\}$

Then the family $\delta=\left\{0_{X}, 1_{X}, M, N\right\}$ is a fuzzy topology.

\subsection{Definition}

Let $X$ be a non empty set and $p$ be a fixed element of $X$. Let $r \epsilon(0,1)$ and $s \in[0,1)$ such that $r-s\langle 1$, then the fuzzy set $p_{s}^{r}(y)=\left\{x, p_{r}(x), p_{s}(x) ; x \in X\right\}$ is called fuzzy point in $X$, where $p_{r}(x)=r$, when $x=y$, otherwise zero, denotes the membership function and $\mathrm{p}_{\mathrm{s}}=\mathrm{r}$, when $\mathrm{x}=\mathrm{y}$, otherwise zero, denotes the reference function.

Note: Let $A=\left\{x, \mu_{A}(x), \gamma_{A}(x) ; x \in X\right\}$. The fuzzy point $p_{s}^{r}=\left\{x, p_{r}(x), p_{s}(x) ; x \in X\right\}$ is contained in $A$ if and only if $\mu_{A}(x) \geq p_{r}(x)$ and $) \gamma_{A}(x) \leq p_{s}(x)$.

\subsection{Definition}

1. Let $A$ and $B$ are two fuzzy sets in $X$ then $A$ and $B$ are said to be intersecting to each other if and only if there exists a point $\mathrm{x} \in \mathrm{X}$ such that $\mathrm{A} \cap \mathrm{B} \neq \phi$.

2. Also, two fuzzy sets $A$ and $B$ are said to be equal if and only if $p \in A \Leftrightarrow p \in B$, for fuzzy point $p$ in $X$.

\subsection{Properties}

Let us consider the family of fuzzy sets $\left\{\mathrm{A}_{\mathrm{i}}\right.$ : $\left.\mathrm{i} \in \mathrm{I}\right\}$ in $\mathrm{X}$ and $\mathrm{P}$ be fuzzy point on $\mathrm{X}$. Then

1. If $\mathrm{P} \in \bigcap\left\{\mathrm{A}_{\mathrm{i}}\right.$ : $\left.\mathrm{i} \in \mathrm{I}\right\}$, then for If $\mathrm{i} \in \mathrm{I}$ we have If $\mathrm{P} \in \mathrm{A}_{\mathrm{i}}$.

2. $\mathrm{f}\left(\mathrm{P}^{\mathrm{C}}\right)=(\mathrm{f}(\mathrm{P}))^{\mathrm{C}}$

It is seen that these properties are easily verified if the complementation is defined on the basis of reference function.

\subsection{Definition}

A fuzzy point $\mathrm{p}$ is said to be quasi-coincident with the fuzzy set $\mathrm{A}$ if $\mathrm{p} \supseteq \mathrm{A}^{\mathrm{C}}$, denoted by $\mathrm{p} q \mathrm{~A}$.

\subsection{Proposition}

Let $(\mathrm{X}, \delta)$ be fuzzy topology. Let $\mathrm{A}$ and $\mathrm{B}$ be two fuzzy sets then $\mathrm{AqB}$ at $\mathrm{x} \Leftrightarrow \mathrm{BqA}$ at $\mathrm{x}$.

\section{Proof}

Case 1 when reference function is zero.

Let $A=\left\{x, \mu_{1}(x), 0 ; x \in X\right\}$ and $B=\left\{x, \mu_{2}(x), 0 ; x \in X\right\}$

Let $\mathrm{AqB}$ at $\mathrm{x} \Rightarrow \mathrm{A} \supseteq \mathrm{B}^{\mathrm{C}}$ at $\mathrm{x}$

$$
\begin{aligned}
& \Rightarrow\left(\mathrm{B}^{\mathrm{C}}\right)^{\mathrm{C}} \supseteq \mathrm{A}^{\mathrm{C}} \text { at } \mathrm{x} \\
& \Rightarrow \mathrm{B} \supseteq \mathrm{A}^{\mathrm{C}} \text { at } \mathrm{x}
\end{aligned}
$$

Hence, $\mathrm{BqA}$ at $\mathrm{X}$

Conversely let $\mathrm{BqA}$ at $\mathrm{x}$

Now $\mathrm{BqA}$ at $\mathrm{x} \Rightarrow \mathrm{B} \supseteq \mathrm{A}^{\mathrm{C}}$ at $\mathrm{x}$

$$
\begin{aligned}
& \Rightarrow\left(\mathrm{A}^{\mathrm{C}}\right)^{\mathrm{C}} \supseteq \mathrm{B}^{\mathrm{C}} \text { at } \mathrm{x} \\
& \Rightarrow \mathrm{A} \supseteq \mathrm{B}^{\mathrm{C}} \text { at } \mathrm{x}
\end{aligned}
$$


Thus AqB at $\mathrm{x}$

Case 2 when reference function is not zero.

Let $A=\left\{x, \mu_{1}(x), \gamma_{1}(x) ; x \in X\right\}$ and $B=\left\{x, \mu_{2}(x), \gamma_{2}(x) ; x \in X\right\}$

And $B^{C}=\left\{x, 1, \mu_{2}(x) ; x \in X\right\} \bigcup\left\{x, \gamma_{2}(x), 0 ; x \in X\right\}$.

Now

Let $\mathrm{AqB}$ at $\mathrm{x} \Rightarrow \mathrm{A} \supseteq \mathrm{B}^{\mathrm{C}}$ at $\mathrm{x}$

$\Rightarrow$ Membership value of $\mathrm{A} \geq$ Membership value of $\mathrm{B}^{\mathrm{C}}$, at $\mathrm{x}$

$\Rightarrow\left(\mu_{1}(\mathrm{x})-\gamma_{1}(\mathrm{x})\right) \geq\left(1-\mu_{2}(\mathrm{x})\right)+\gamma_{2}(\mathrm{x})$

$\Rightarrow 1-\left(\mu_{1}(\mathrm{x})-\gamma_{1}(\mathrm{x})\right) \leq 1-\left(1-\mu_{2}(\mathrm{x})\right)+\gamma_{2}(\mathrm{x})$

$\Rightarrow 1-\left(\mu_{1}(\mathrm{x})-\gamma_{1}(\mathrm{x})\right) \leq\left(\mu_{2}(\mathrm{x})\right)-\gamma_{2}(\mathrm{x})$

$\Rightarrow$ Membership value of $\mathrm{A}^{\mathrm{C}} \leq$ Membership value of $\mathrm{B}$

$\Rightarrow \mathrm{BqA}$ at $\mathrm{x}$

Conversely let $\mathrm{BqA}$ then $\mathrm{A}^{\mathrm{C}}=\left\{\mathrm{x}, 1, \mu_{1}(\mathrm{x}) ; \mathrm{x} \in \mathrm{X}\right\} \bigcup\left\{\mathrm{x}, \gamma_{1}(\mathrm{x}), 0 ; \mathrm{x} \in \mathrm{X}\right\}$.

Now $\mathrm{BqA}$ at $\mathrm{x} \Rightarrow \mathrm{B} \supseteq \mathrm{A}^{\mathrm{C}}$ at $\mathrm{x}$

$\Rightarrow$ Membership value of $\mathrm{B} \geq$ Membership value of $\mathrm{A}^{\mathrm{C}}$ at $\mathrm{x}$

$\Rightarrow\left(\mu_{2}(\mathrm{x})-\gamma_{2}(\mathrm{x})\right) \geq\left(1-\mu_{1}(\mathrm{x})\right)+\gamma_{1}(\mathrm{x})$

$\Rightarrow 1-\left(\mu_{2}(\mathrm{x})-\gamma_{2}(\mathrm{x})\right) \leq 1-\left(1-\mu_{1}(\mathrm{x})\right)+\gamma_{1}(\mathrm{x})$

$\Rightarrow 1-\left(\mu_{2}(\mathrm{x})-\gamma_{2}(\mathrm{x})\right) \leq\left(\mu_{1}(\mathrm{x})\right)-\gamma_{1}(\mathrm{x})$

$\Rightarrow$ Membership value of $\mathrm{B}^{\mathrm{C}} \leq$ Membership value of $\mathrm{A}$, at $\mathrm{x}$

$\Rightarrow \mathrm{AqB}$, at $\mathrm{x}$

Hence $\mathrm{AqB}$ at $\mathrm{x} \Leftrightarrow \mathrm{BqA}$ at $\mathrm{x}$.

\subsection{Proposition}

Let $(\mathrm{X}, \delta)$ be fuzzy topology. Let $\mathrm{A}$ and $\mathrm{B}$ be two fuzzy sets then $\mathrm{AqB} \Leftrightarrow \mathrm{BqA}$.

Proof we can prove this proposition by following prove of the proposition1.

\subsection{Proposition}

Let $(\mathrm{X}, \delta)$ be fuzzy topology. Let $\mathrm{A}, \mathrm{B}$ and $\mathrm{C}$ be fuzzy sets, if $\mathrm{A} \subseteq \mathrm{B}$ then $\mathrm{CqA} \Rightarrow \mathrm{CqB}$.

Proof

Case 1 when reference function is zero.

Let $A=\left\{x, \mu_{1}(x), 0 ; x \in X\right\}, B=\left\{x, \mu_{2}(x), 0 ; x \in X\right\}$ and $C=\left\{x, \mu_{3}(x), 0 ; x \in X\right\}$.

We have $\mathrm{A} \subseteq \mathrm{B}$ so clearly $\mu_{1}(\mathrm{x}) \leq \mu_{2}(\mathrm{x})$.

Now

$\mathrm{CqA} \Rightarrow \mathrm{C} \supseteq \mathrm{A}^{\mathrm{C}}$

Since $\mathrm{A} \subseteq \mathrm{B} \Rightarrow \mathrm{B}^{\mathrm{C}} \subseteq \mathrm{A}^{\mathrm{C}}$.

So $\mathrm{CqA} \Rightarrow \mathrm{C} \supseteq \mathrm{A}^{\mathrm{C}} \supseteq \mathrm{B}^{\mathrm{C}}$

$\Rightarrow \mathrm{C} \supseteq \mathrm{B}^{\mathrm{C}}$

$\Rightarrow \mathrm{CqB}$

Case 2 When reference function is not zero. 
Let $A=\left\{x, \mu_{1}(x), \gamma_{1}(x) ; x \in X\right\}, B=\left\{x, \mu_{2}(x), \gamma_{2}(x) ; x \in X\right\}$ and $C=\left\{x, \mu_{3}(x), \gamma_{3}(x) ; x \in X\right\}$.

Also, $A^{C}=\left\{x, 1, \mu_{1}(x) ; x \in X\right\} \bigcup\left\{x, \gamma_{1}(x), 0 ; x \in X\right\}, B^{C}=\left\{x, 1, \mu_{2}(x) ; x \in X\right\} \bigcup\left\{x, \gamma_{2}(x), 0 ; x \in X\right\}$.

Now

$\mathrm{CqA} \Rightarrow \mathrm{C} \supseteq \mathrm{A}^{\mathrm{C}}$

$\Rightarrow$ Membership value of $\mathrm{C} \geq$ Membership value of $\mathrm{A}^{\mathrm{C}}$

$\Rightarrow\left(\mu_{3}(\mathrm{x})-\gamma_{3}(\mathrm{x})\right) \geq\left(1-\mu_{1}(\mathrm{x})\right)+\gamma_{1}(\mathrm{x})$

Again as

$\mathrm{A} \subseteq \mathrm{B} \Rightarrow \mathrm{B}^{\mathrm{C}} \subseteq \mathrm{A}^{\mathrm{C}}$

$\Rightarrow$ Membership value of $\mathrm{B}^{\mathrm{C}} \leq$ Membership value of $\mathrm{A}^{\mathrm{C}}$

Hence

$\Rightarrow\left(1-\mu_{2}(\mathrm{x})\right)+\gamma_{2}(\mathrm{x}) \leq\left(1-\mu_{1}(\mathrm{x})\right)+\gamma_{1}(\mathrm{x})$.

$$
\begin{aligned}
\mathrm{CqA} & \Rightarrow\left(\mu_{3}(\mathrm{x})-\gamma_{3}(\mathrm{x})\right) \geq\left(1-\mu_{1}(\mathrm{x})\right)+\gamma_{1}(\mathrm{x}) \geq\left(1-\mu_{2}(\mathrm{x})\right)+\gamma_{2}(\mathrm{x}) \\
& \Rightarrow\left(\mu_{3}(\mathrm{x})-\gamma_{3}(\mathrm{x})\right) \geq\left(1-\mu_{2}(\mathrm{x})\right)+\gamma_{2}(\mathrm{x}) \\
& \Rightarrow \mathrm{C} \supseteq \mathrm{B}^{\mathrm{C}} \\
& \Rightarrow \mathrm{CqB}
\end{aligned}
$$

Therefore when $\mathrm{A} \subseteq \mathrm{B}$ then $\mathrm{CqA} \Rightarrow \mathrm{CqB}$.

\subsection{Proposition}

Let $(\mathrm{X}, \delta)$ be fuzzy topology. Let $\mathrm{A}, \mathrm{B}$ fuzzy sets, if $\mathrm{A} \subseteq \mathrm{B}$ then pqA $\Rightarrow \mathrm{pqB}$.

Proof Prove is straightforward.

\subsection{Proposition}

Let $(\mathrm{X}, \delta)$ and $(\mathrm{Y}, \Gamma)$ be two fuzzy topological spaces and let $\mathrm{A}$ and $\mathrm{B}$ be fuzzy sets. Let $\mathrm{f}$ be a function from $\mathrm{X}$ to $\mathrm{Y}$ then
i. $\quad \operatorname{Aqf}^{-1}(B) \Leftrightarrow f(A) q B$
ii. $\quad A q B \Rightarrow f(A) q f(B)$
iii. $\mathrm{f}^{-1}(\mathrm{~A}) \mathrm{qf}^{-1}(\mathrm{~B}) \Rightarrow \mathrm{AqB}$

(i) Proof

$$
\begin{aligned}
& \text { We have } \operatorname{Aqf}^{-1}(B) \Rightarrow A \supseteq\left(\mathrm{f}^{-1}(B)\right)^{C} \\
& \Rightarrow A \supseteq\left(f^{-1}\left(B^{C}\right)\right) \\
& \left.\Rightarrow f(A) \supseteq f^{-1}\left(B^{C}\right)\right) \\
& \Rightarrow f(A) \supseteq B^{C} \\
& \Rightarrow f(A) q B
\end{aligned}
$$

Conversely let $\mathrm{f}(\mathrm{A}) \mathrm{qB}$.

Now

$$
\begin{aligned}
\mathrm{f}(\mathrm{A}) \mathrm{qB} & \Rightarrow \mathrm{f}(\mathrm{A}) \supseteq \mathrm{B}^{\mathrm{C}} \\
& \Rightarrow \mathrm{f}^{-1}(\mathrm{f}(\mathrm{A})) \supseteq \mathrm{f}^{-1}\left(\mathrm{~B}^{\mathrm{C}}\right) \\
& \Rightarrow \mathrm{A} \supseteq\left(\mathrm{f}^{-1}(\mathrm{~B})\right)^{\mathrm{C}} \\
& \Rightarrow \operatorname{Aqf}^{-1}(\mathrm{~B})
\end{aligned}
$$


Hence $\operatorname{Aqf}^{-1}(B) \Leftrightarrow \mathrm{f}(\mathrm{A}) \mathrm{qB}$.

(ii) Proof

Let $\mathrm{AqB} \Rightarrow \mathrm{A} \supseteq \mathrm{B}^{\mathrm{C}}$

Now

$$
\begin{aligned}
f(A)(y) & =\bigcup\{A(x) ; x \in X: f(x)=y\} \\
& \supseteq \bigcap\left\{B^{C}(x) ; x \in X: f(x)=y\right\}, \text { as } A \supseteq B^{C} \\
& =(\bigcup\{B(x) ; x \in X: f(x)=y\})^{C} \\
& =(f(B))^{C}
\end{aligned}
$$

$\Rightarrow \mathrm{f}(\mathrm{A}) \mathrm{q} \mathrm{f}(\mathrm{B})$

Hence $\mathrm{AqB} \Rightarrow \mathrm{f}(\mathrm{A}) \mathrm{q} \mathrm{f}(\mathrm{B})$

(iii) Proof

The prove is straightforward following prove of $\mathrm{i}$ and ii.

\section{Conclusion}

In this article we attempted extended definition of complementation of fuzzy set on the basis of reference function to give definition of fuzzy point and quasi-coincidence for fuzzy point because there are some drawbacks in the existing definition of complement of fuzzy sets. In this article the definition of complement of fuzzy set proposed by Baruah $[2,3]$ can be seen as a particular case of what we are giving. We give value our definition of complement of an extended definition of fuzzy set with example which was discussed very nicely by Baruah [2,3] and show that indeed our definition satisfies all those properties that complement of a set really does in classical sense. By observing this idea we used extended definition of fuzzy set to define fuzzy point and quasi coincident for fuzzy point because complement of fuzzy set plays important role to define fuzzy point and quasi coincident for fuzzy point. The main purpose of this article is to revisit and comment on some results associated with the existing definition of complementation of fuzzy sets. These results which are associated with existing definition of fuzzy sets are discussed from the standpoints of the new definition of complementation of fuzzy sets on the basis of reference function also some proposition are proved. It is accepted that these new definitions would be able to remove the drawbacks that exist. We have seen that if we used the extended definition of fuzzy set and complement of an extended definition of fuzzy set then we arrive at the conclusion that the fuzzy sets too follow the set theoretic axioms. We hope that this work will help for further work of fuzzy topology.

\section{References}

[1] Zadeh L. A., Fuzzy sets, Information and Control, 8, 338-353 (1965).

[2] Baruah H. K., Towards Forming a Field of Fuzzy Sets, Int. Jr. of Energy, Information and Communications, Vol. 2, issue 1, Feb. (2011).

[3] Baruah H. K., The Theory of Fuzzy Sets: Belief and Realities, Int. Jr. of Energy, Information and Communications, 1-22Vol. 2, issue 2, May (2011).

[4] Chang C. L., Fuzzy Topological Space, Journal of Mathematical Analysis and Application 24, 182- 190 (1968).

[5] Basuatary B., Towards Forming the Field of Fuzzy Closure with Reference to Fuzzy Boundary, JPMNT, 
Vol. 4, No.1, pp30-34.

[6] Atanassov K. T., Intuitionistic fuzzy sets, Fuzzy sets and systems, 20, 87-96, (1986).

[7] Coker D., An introduction to Intuitionistic fuzzy topological spaces, Fuzzy sets and systems, 88, 81-89, (1997).

[8] Pu P. M. and Liu Y. M., Fuzzy Topology I Neighbourhood Structure of a Fuzzy Point and OORE-Smith Convergence, J.Math.Anal Appl. 76(1980), No.2, 571-599.

[9] Coker D.and Demirci M., On Intuitionistic Fuzzy Points, Notes IFS 1(1995), No. 2, 79-84.

[10] Shi W. and Liu K., A Fuzzy Topology for Computing the Interior, Boundary and Exterior of Spatial Objects Quantitatively in GIS, Computers and Geosciences 33 (2007) 898-915.

[11] Baruah H. K., The Randomness-Fuzziness Consistency Principle, Int. Jr. of Energy, Information and Communications, Vol. 1, Issue 1, November, (2010).

[12] Baruah H. K., In Search of the Root of Fuzzyness: The Measure Theoretic Meaning of Partial Presence, Annals of Fuzzy Mathematics and Informatics, Vol. 2 No. 1, (July 2011), pp. 57-68.

[13] Lupianez F. G., Quasicoincident for Intuitionistic Fuzzy Points, Int. J. of Mathematics and Mathematical Sciences 2005:10(2005) 1539-1542.

[14] Patil D. B. and Dongre Y. V., A Fuzzy Approach for Text Mining, I. J. Mathematical Sciences and Computing, 2015, 4, 34-43.

[15] Palaniappan N., Fuzzy Topology, CRC Press, Florida, 2002.

\section{Authors' Profiles}

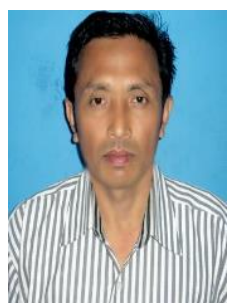

Kangujam Priyokumar Singh was born at Kakwa Lamdaibong, Imphal, Manipur (India). At present he is the faculty member of Department of Mathematical Sciences, Bodoland University, Kokrajhar, Assam, India. He was the former Head, Department of Mathematical Sciences and Dean, Faculty of Science and Technology, Bodoland University. He published one book and more than 35(thirty five) research papers in international Journals in the field of Pure and Applied Mathematics. He attained and presented many papers in international and national seminars and conferences in the field of Mathematics.

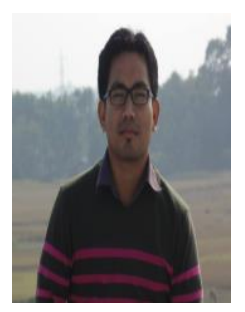

Bhimraj Basumatary is a research scholar of Department of Mathematical Sciences, Bodoland University, Kokrajhar, BTC, Assam, India. He has published more than 6(six) research articles.

How to cite this paper: Kangujam Priyokumar Singh, Bhimraj Basumatary,"A Note on Quasi-coincidence for Fuzzy Points of Fuzzy Topology on the Basis of Reference Function", International Journal of Mathematical Sciences and Computing(IJMSC), Vol.2, No.3, pp.49-57, 2016.DOI: 10.5815/ijmsc.2016.03.05 